\title{
Cellular congenital mesoblastic nephroma detected by prenatal MRI: a case report and literature review
}

\author{
Tingting Liu ${ }^{1}$, Lika'a Fasih Y. Al-Kzayer ${ }^{2}$, Shamil Naji Sarsam ${ }^{3}$, Lei Chen ${ }^{4}$, Raghad M. Saeed ${ }^{5}$, \\ Kenan Hussien $\mathrm{Ali}^{6}$, Yozo Nakazawa ${ }^{2}$ \\ ${ }^{1}$ Department of Pediatric Hematology/Oncology, Xinhua Hospital, Shanghai Jiaotong University School of Medicine, Shanghai, China; ${ }^{2}$ Department \\ of Pediatrics, Shinshu University School of Medicine, Matsumoto, Nagano, Japan; ${ }^{3}$ Department of Radiology, Ibn Al-Nafees Hospital, Manama, \\ Kingdom of Bahrain; ${ }^{4}$ Department of Pathology, Xinhua Hospital, Shanghai Jiaotong University School of Medicine, Shanghai, China; ${ }^{5}$ Department \\ of Pediatric Oncology, Children Welfare Teaching Hospital, Baghdad Medical City, Baghdad, Iraq; ${ }^{6}$ Department of Family Medicine, Baghdad \\ University, College of Medicine, Baghdad, Iraq \\ Correspondence to: Lei Chen, MD, PhD. Department of Pathology, Xinhua Hospital, Shanghai Jiaotong University, School of Medicine, Kongjiang \\ Road 1665, Shanghai 200092, China. Email: chenlei02@xinhuamed.com.cn.
}

\begin{abstract}
Congenital mesoblastic nephroma $(\mathrm{CMN})$ is a rare tumor, yet it is the most frequently diagnosed renal neoplasm in the first 3 months of life. CMN reports with prenatal magnetic resonance imaging (MRI) are scarce. Our aims were to describe a case with fetal MR imaging along with other findings, and to review the literature concerned with prenatal MRI detection of CMN. Upon routine ultrasound (US) examination of a 36-week pregnant woman, a fetal abdominal mass was disclosed. Prenatal MRI revealed a large, well-circumscribed renal mass of solid and cystic components, not invading the adjacent tissues, but compressing normal renal parenchyma of the lower pole of the left kidney. Thus, a low malignant renal tumor was considered. After Cesarean delivery, imaging including US and computerized tomography (CT) scan was performed on the apparently healthy boy and verified the prenatal MRI finding. Accordingly, left nephrectomy was performed at the age of 12 days. The pathology confirmed CT results of the solid and cystic components of the mass, in addition to the necrotic and hemorrhagic constitution. Cellular CMN was diagnosed, and ETV6 gene rearrangement was demonstrated by FISH analysis. No recurrence was detected within the 40 months follow-up after the operation. Our report described a rare and seldomly detected renal tumor in utero with the aid of MRI and reviewed the few related reports in the literature in which MRI was performed prenatally. This report also highlights the need for prenatal MRI as a complementary tool to US in cases with suspected fetal renal mass and recommends its use for carefully managing the possible risks during the perinatal period.
\end{abstract}

Keywords: Congenital mesoblastic nephroma (CMN); cellular CMN; case report; prenatal MRI; ETV6

Submitted Jun 22, 2021. Accepted for publication Nov 01, 2021.

doi: 10.21037/tp-21-289

View this article at: https://dx.doi.org/10.21037/tp-21-289

\section{Introduction}

Renal tumors in fetuses and infants younger than 6 months of age are rare. Although, congenital mesoblastic nephroma $(\mathrm{CMN})$ represents approximately $3 \%$ of all pediatric renal tumors, it is the most frequently diagnosed renal neoplasm within the first 3 months of life (1-3).

Previously, CMN was considered a benign tumor but reports of recurrent and/or metastatic cases had changed that perception. Accordingly, CMN is considered as a neoplasm of low malignant potential (2). Although ultrasonography (US) including color Doppler sonography (CDS) is valuable in the initial assessment of fetal renal masses, magnetic resonance imaging (MRI) is required for further evaluation. Fetal MRI which uses no ionizing radiation, allows excellent detailed imaging of the fetus 
in utero through a better soft tissue contrast, together with multi-sequences and multiplanes with no significant limitation by maternal obesity or fetal orientation. Furthermore, it aids in the detection of fetal anomalies including renal masses along with identification of the organ of origin, the size, and the nature of the mass (4-6). Thus, it facilitates decision making particularly with the presence of perinatal risk factors that challenge the mode of delivery. The implementation of single-shot fast-spin echo (SSFSE)MRI technique, has effectively limited the problems related to fetal movement. The length, signal intensity on T2weighted images (T2WI), and apparent diffusion coefficient of the fetal kidney change significantly with gestational age, providing more clues for antenatal diagnosis (7). Solid components of $\mathrm{CMN}$ shows low signal on $\mathrm{T} 1$, and high signal on T2WI (3).

Computed tomography (CT) scan is the gold standard for the diagnosis of renal tumors and the assessment of potential metastases (8). However, CT during pregnancy carries a risk of exposing the fetus to radiation (3). Postnatal enhanced CT is helpful to evaluate tumor composition and biological behavior of a renal tumor. CT images can depict intra-tumoral hemorrhage, necrosis, peripheral structures, and the remaining normal renal parenchyma, as well as metastases (9).

Complete nephrectomy including surrounding adipose tissue, is the approved management of CMN with an overall survival rate of $95 \%(2,10)$. Definite diagnosis of CMN should be established only by histopathology (11). Histopathologic classification of CMN includes classic, cellular, and mixed subtypes (1). $\mathrm{t}(12 ; 15)(\mathrm{p} 13 ; \mathrm{q} 25)$ associated ETV6-NTRK3 gene fusions described in infantile fibrosarcoma are also present in $\mathrm{CMN}(1,10)$.

Although the outcome of CMN is generally excellent, poor prognostic factors are present, such as cellular CMN variant, onset in infant older than 3 months, and advanced clinical stage $(1,10)$. However, the majority of cellular CMN cases which possess ETV6-NTRK3 gene fusion, have a superior 5 -year relapse-free survival (12).

Notably, papers reporting about fetal MRI features of CMN are limited due to its rarity and the fact that only about $15 \%$ of $\mathrm{CMN}$ cases can be diagnosed prenatally (1). Otherwise, most $\mathrm{CMN}$ cases were reported after birth.

Herein we describe a case of cellular CMN, detected prenatally by MRI, and postnatally by CT scan, along with the clinical and pathogenetic data and we review the literature for similar cases in respect to the prenatal diagnosis using MRI.
We present the following case in accordance with the CARE reporting checklist (available at https:// tp.amegroups.com/article/view/10.21037/tp-21-289/rc).

\section{Case presentation}

During a routine US examination, a 36-year-old nulliparous woman with natural pregnancy at 36-week of gestation was found to have a fetus with an abdominal mass. Apart from the increasing fetal abdominal mass, the woman had uneventful maternal and obstetric history with unremarkable previous US results, and she denied any exposure to chemical or radioactive materials. Before proceeding to the MRI, another US was performed in our hospital at 36 weeks' gestation and showed an increased amniotic fluid index of $19.3 \mathrm{~cm}$, along with the confirmation of the fetal abdominal mass. As shown in Figure 1A-1D, MRI revealed a large well-circumscribed fetal left kidney mass, measuring $6.3 \mathrm{~cm} \times 5.7 \mathrm{~cm} \times 5.3 \mathrm{~cm}$, not invading the adjacent tissues, but compressing the normal parenchyma of the lower pole of the left kidney. The mass presented with heterogeneous resolution, containing in addition to some cystic areas, a predominantly solid components characterized by low signal intensity on T1WI, and intermediate signal intensity on T2WI, with signal restriction in diffusion weighted images (DWI).

Another US was performed 21 hours before birth, showed a left renal mass measuring $7.4 \mathrm{~cm} \times 7.1 \mathrm{~cm} \times 5.6 \mathrm{~cm}$ (Figure $1 E, 1 F$ ), with a heterogeneous echo of solid and cystic areas and a CDS image of relatively increased blood flow. Given the features of the prenatal MRI, a presumptive diagnosis of CMN was considered, and the parents were counseled about the diagnosis and perinatal risks. A boy weighing 3,560 grams was born via elective Cesareansection (CS) at 38-week gestation, with Apgar scores of 9 and 10 at 1 and 5 minutes, respectively. Although the neonate was active without distress, there was a palpable mass in the left lower abdomen, felt bimanually. US was done 5 hours after birth and showed a heterogeneous echogenic solid mass with anechoic zone, measuring $7.4 \mathrm{~cm} \times 7.2 \mathrm{~cm} \times 5.5 \mathrm{~cm}$ (Figure $2 A, 2 B$ ), while CDS imaging demonstrated more blood flow than did the prenatal US. Post-enhanced CT, which included a chest scan, was performed at 4 days (Figure $2 C-2 F$ ). CT revealed a left renal mass measuring $7.8 \mathrm{~cm} \times 7.6 \mathrm{~cm} \times 6.3 \mathrm{~cm}$, of welldefined boundary and expansive growth pattern beyond the space of the affected kidney. The mass presented with solid and cystic components, necrosis and hemorrhage, with the 

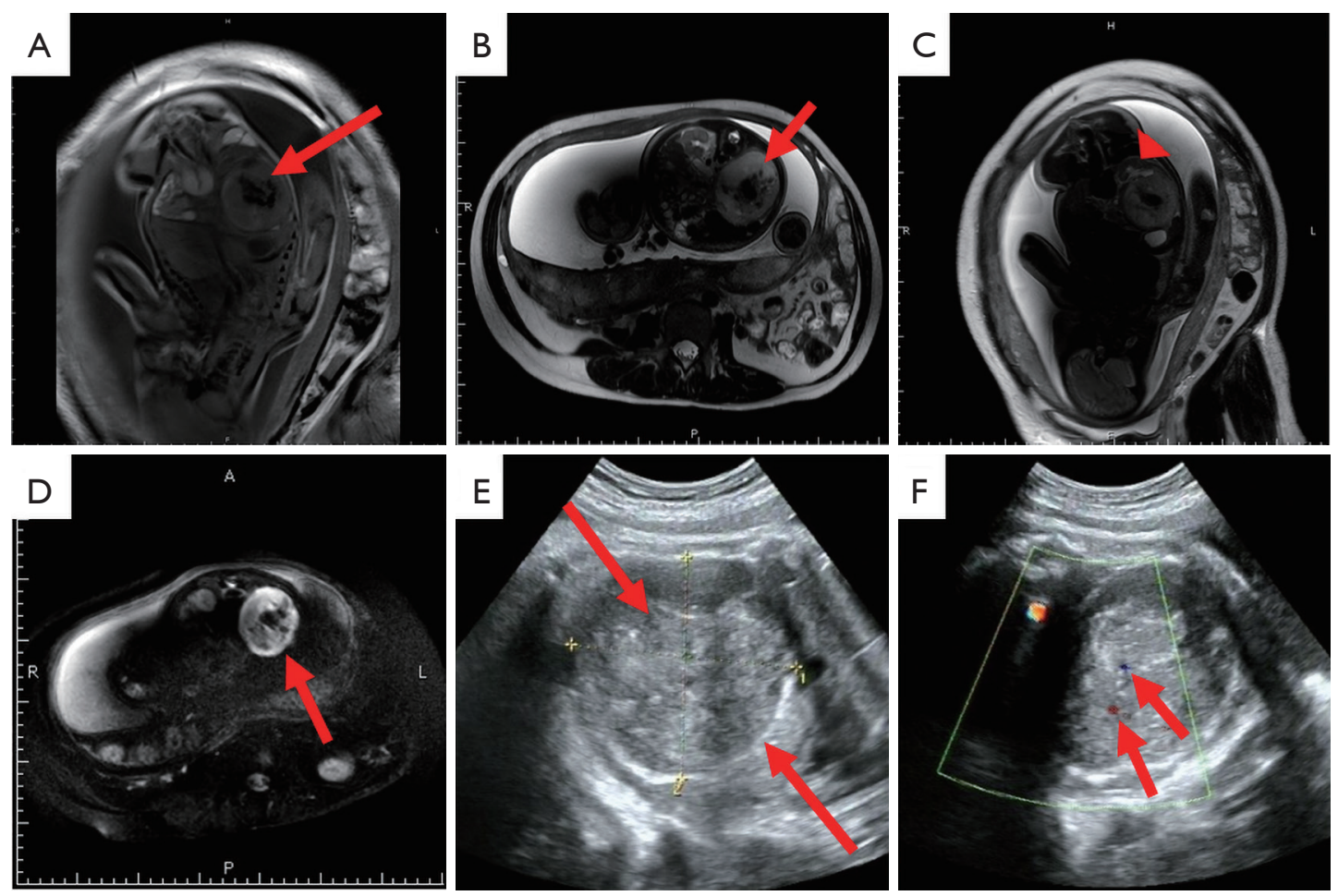

Figure 1 Prenatal imaging characteristics of CMN in our case (fetal period). (A-D) Prenatal MRI. (A) Coronal T1WI reveals a left renal mass with heterogeneous signals, appearing as low signal of the solid portion (arrowed); on axial (B) and sagittal (C) T2WI, the mass predominantly showed intermediate signal intensity (arrowed in B), with multiple regions of low signal intensity. The structure of the affected left-side kidney is compressed (arrowed in C); (D) DWI showed diffusion restriction in the solid portions of the tumor (arrowed). (E,F) Prenatal US. (E) US image showed a unilateral encapsulated mass in the left kidney (arrowed from two directions); (F) CDS image showed the presence of blood flow (arrowed). CMN, congenital mesoblastic nephroma; MRI, magnetic resonance imaging; T1WI, T1 weighted images; T2WI, T2 weighted images; DWI, diffusion weighted image; US, ultrasound; CDS, color Doppler sonography.

solid region showing contrast enhancement. Furthermore, normal renal parenchyma and adjacent tissues surrounding the tumor were compressed, without perinephric invasion or enlargement of the lymph nodes.

Clinically, the neonate developed hypertension and intravenous infusion of nicardipine, a dihydropyridine calcium channel blocker, was given. The neonate was kept in intensive care and underwent nephrectomy at 12-day-old. The left kidney along with the mass and perirenal fat, were removed. The child showed no signs of disease progression or recurrence after 40 months of follow-up, providing that no chemotherapy was used.

Pathologically, the mass occupied most of the kidney, and a small rim of residual kidney tissue was seen at part of edge of the tumor with a clear boundary. The mass was composed of solid and cystic components with necrotic, and hemorrhagic constitution. Microscopically, the tumor was composed of spindle-shaped cells, arranged in bundles and poorly formed interlacing fascicles. Tumor cells showed high cellularity with tapered or elliptical nuclei and a high mitotic rate. Islands of renal parenchyma entrapped in tumor cells were observed. Multiple hemorrhagic and necrotic lesions in addition to cystic zones were identified (Figure 3A,3B). The tumor cells were positive for vimentin (VIM) and WT1 antibodies, with the latter showing a diffusely nuclear staining positivity pattern, meanwhile, P53 was heterogeneously positive. Additionally, Ki-67 was extensively positive in $>60 \%$, while cyclin D1 was positive in $<10 \%$ of the tumor cells (Figure 3C-3G). ETV6 gene rearrangement was demonstrated by FISH (Figure $3 H$ ). Thus, the diagnosis of cellular CMN was made based on the pathology.

All procedures performed in studies involving human participants were in accordance with the ethical standards of 

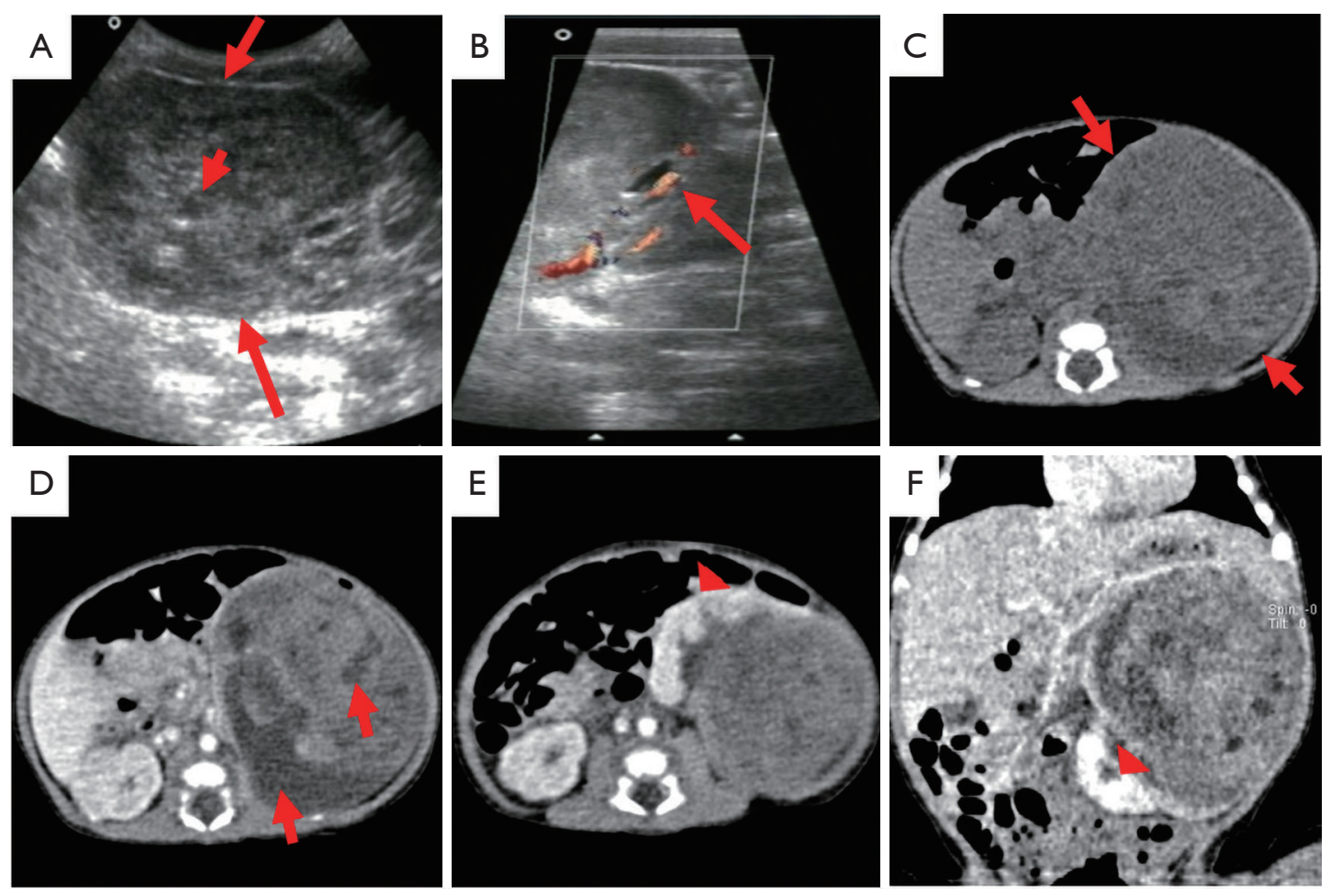

Figure 2 Postnatal imaging evaluation of CMN in our case (neonatal period). (A,B) Postnatal US. (A) US image showed a heterogeneous echogenic solid mass (arrowed) with multiple anechoic zones (arrowhead); (B) CDS image demonstrated more blood flow than the prenatal US (arrowed). (C-F) Postnatal CT scan. (C) Axial non-contrast CT image revealed a heterogeneous, well-circumscribed mass in the left kidney (arrowed); (D) axial contrast-enhanced CT scan in the portal venous phase demonstrates the enhancement of the solid components, without the enhancement of the cystic and necrotic components (arrowed); (E) the normal structure of the affected left-side kidney was compressed (arrowed); (F) coronal image of contrast-enhanced CT exhibits the compression of the adjacent tissues by the renal tumor. The compressed remaining normal part of the kidney is arrowed. CMN, congenital mesoblastic nephroma; US, ultrasound; CDS, color Doppler sonography.

the institutional and/or national research committee(s) and with the Helsinki Declaration (as revised in 2013). Written informed consent was obtained from the patient's parent for publication of this case report and accompanying images. A copy of the written consent is available for review by the editorial office of this journal.

\section{Discussion and review of the literature}

Around $5 \%$ of perinatal tumors arise from the kidney, and $\mathrm{CMN}$ comes on the top of the list of fetal/neonatal renal mass as a differential diagnosis, followed by Wilms tumor, rhabdoid tumor, and clear cell sarcoma of the kidney, whereas the main nonrenal differential diagnosis is neuroblastoma $(3,13)$.

Prenatal MRI finding in CMN albeit nonspecific, it generally shows a well-defined, homogeneously solid mass, and tends to be isointense to normal renal parenchyma on T2WI (6). On MRI the tumor can be distinguished from fetal kidney and adrenal gland, therefore, a congenital neuroblastoma, which arises mostly from adrenal gland, can be identified. Remarkably, encasement of the adjacent structures and blood vessels, in addition to calcification that can be seen as blooming artifacts in MRI, are features of neuroblastoma but not CMN $(3,4,11)$. Thus, prenatal MRI provides an early and detailed description about a fetal renal mass and makes early perinatal or postnatal intervention possible in terms of clinical and surgical approach. Indeed, the likelihood of a renal mass being malignant in origin increases with older age of presentation after 3 months of age. It is recommended that all primary renal tumors diagnosed in infants younger than 6 months should be 

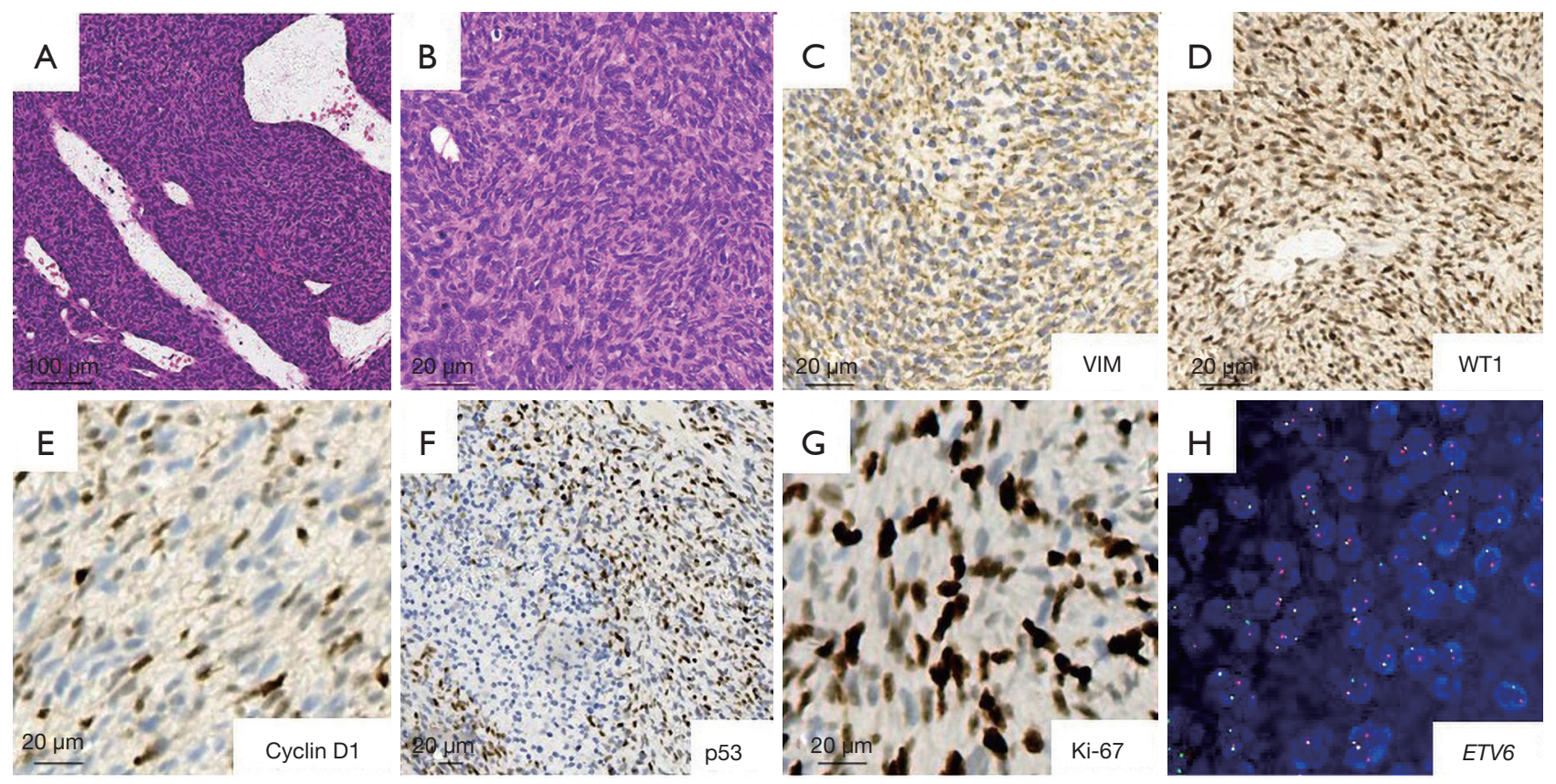

Figure 3 Histopathological and cytogenetic characteristics of the tumor. The tumor was composed of spindle-shaped cells, arranged in bundles and poorly formed interlacing fascicles. (A) H\&E, original magnification $\times 100$; (B) Necrotic lesions and cystic zone were identified $(\mathrm{H} \& \mathrm{E})$, original magnification $\times 400$; Tumor cells showed consistent expression for VIM (C) and WT1 (D), but heterogeneous staining for cyclin D1 (positive in $<10 \%$ of tumor cells); (E,F) P53 manifested heterogeneous positivity, magnification $\times 200$; (G) Ki-67 expressed extensive positivity in $>60 \%$ of the tumor cells; $(\mathrm{H}) \mathrm{FISH}$ analysis revealed ETV6 gene rearrangement. The magnification $(\times 400)$ was used in C, D, E, G, and H. VIM, vimentin.

treated with immediate nephrectomy due to the high chance of non-Wilms tumor etiology $(2,8)$.

A review of over 47 years of data on fetal and neonatal renal masses revealed that about a quarter of the total studied CMN cases were antenatally diagnosed, and that an abdominal mass was detected by prenatal US in $14 \%$ of the 34 fetal CMN cases, while an abdominal mass was palpated in $42 \%$ of the 105 neonatal CMN cases (13). England et al. reported a total of $47 \mathrm{CMN}$ cases registered in the United Kingdom Children's Cancer and Leukaemia Group over 17 years, with an antenatal diagnosis for about $30 \%$ of the cases, whereas in $17 \%$ of cases, $\mathrm{CMN}$ was detected through routine clinical examination after birth (2).

As shown in Table 1 and Table 2, we reviewed the literature for the CMN cases that were reported with the prenatal MRI. Generally, CMN was described as a clearly defined and homogeneous solid mass arising from the kidney, with the biggest fetal mass detected by MRI was measuring $8 \mathrm{~cm} \times 9 \mathrm{~cm} \times 10 \mathrm{~cm}$. A huge CMN was reported by Ko et al. had replaced the ipsilateral kidney, and displaced the contralateral kidney as well as the other surrounding organs, in addition, the solid portions in the mass were showing multiple cystic spaces (18). Linam et al. reported a CMN that caused compression of adjacent liver in utero (6). Restriction of the diffusion on DWI was reported in 2 fetuses as in our case $(18,20)$. Additionally, absence of necrosis or hemorrhage in the mass was mentioned in 2 reports $(16,18)$. The earliest fetal CMN detected by MRI was at $22^{+3}$ weeks of gestation, however, the patient died soon after birth because of hydrops fetalis, which was previously reported in the literature as a rare lethal complication of CMN (15). Most cases (8/10) were diagnosed in the third trimester, with a mean of 33 [27-36] gestational weeks. Seven cases had the $\mathrm{CMN}$ on the right side, while our case like the 3 remaining cases had the $\mathrm{CMN}$ on the left. Comparably, $\mathrm{CMN}$ was reported to have a relatively similar distribution in right and left kidneys, but never bilateral $(1,2,13)$. Polyhydramnios was presented in $(8 / 10)$ cases, and it was mentioned to be frequently associated with $\mathrm{CMN}(5,6,19)$. In 3 reports postnatal MRI was performed, but in one case the MRI was postoperatively done upon recurrence. Postnatal MRI just like fetal MRI 
Table 1 Congenital mesoblastic nephroma with prenatal MRI diagnosis in the literature review (published from 1993-2006)

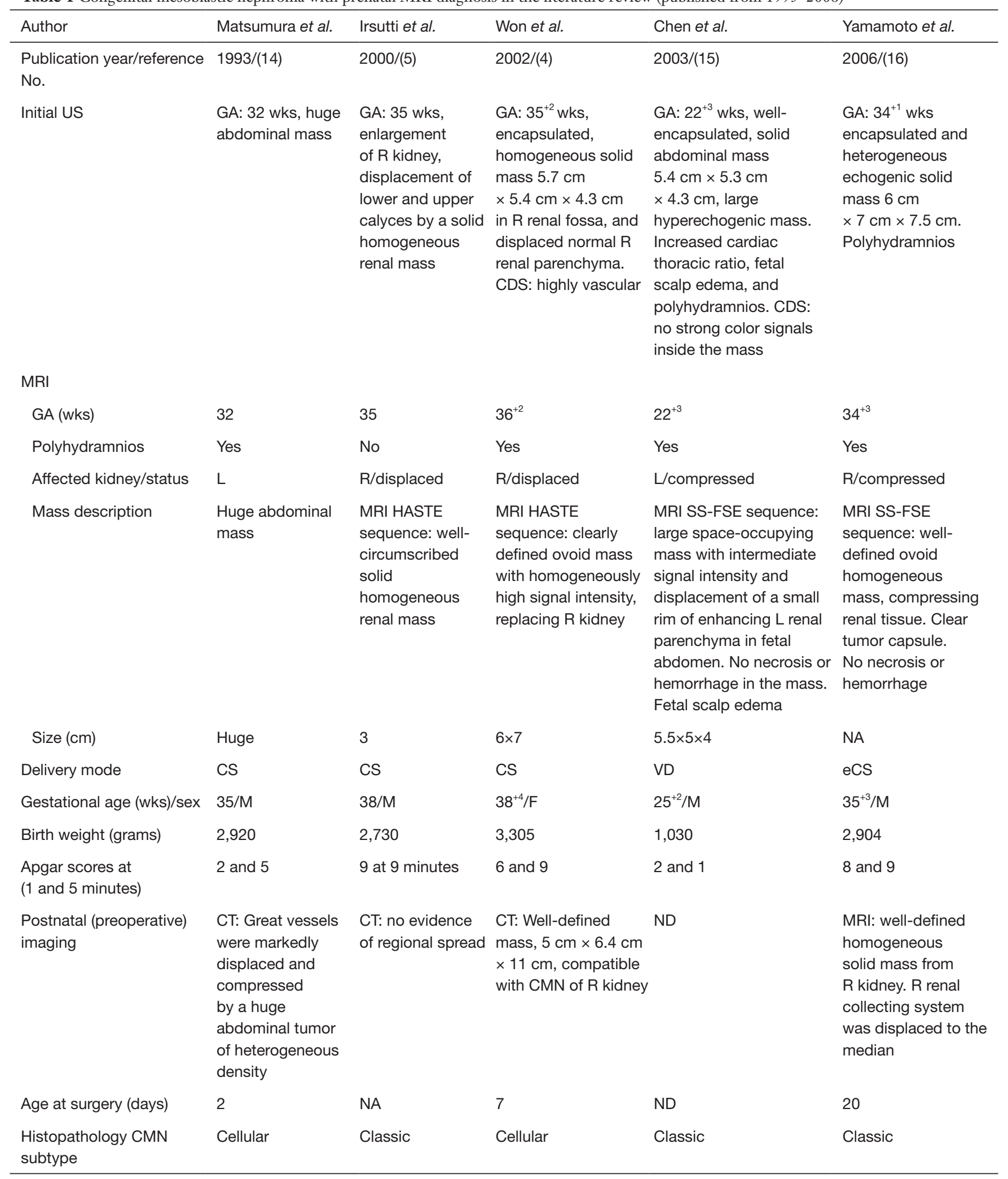

Table 1 (continued) 
Table 1 (continued)

\begin{tabular}{llllll}
\hline Author & Matsumura et al. & Irsutti et al. & Won et al. & Chen et al. & Yamamoto et al. \\
\hline Genetic evaluation & ND & ND & ND & ND & ND \\
Outcome/follow up age & Cured/2 years & Cured/10 months & Fine/2 weeks & Died soon after birth & Cured/1 years \\
Complications after birth & $\begin{array}{l}\text { Asphyxia, heart } \\
\text { failure. Mechanical } \\
\text { ventilation was } \\
\text { used. Tumor rupture }\end{array}$ & None & Premature, hydrops & Premature, breech \\
& $\begin{array}{l}\text { 2 days after birth, } \\
\text { and emergency } \\
\text { surgery was done }\end{array}$ & & & \\
& & & \\
\hline
\end{tabular}

CDS, color Doppler sonography; CMN, congenital mesoblastic nephroma; CS, Cesarean-section; CT, computed tomography; eCS, emergency Cesarean-section; F, female; GA, gestational age; HASTE, Half-Fourier acquisition single-shot turbo-spin-echo; L, left; NA, not available; M, male; MRI, magnetic resonance imaging; ND, not done; R, right; SS-FSE, single shot fast spin echo; US, ultrasound; VD, vaginal delivery; wks, weeks.

showed a CMN mass with a low signal intensity on T1WI sequences, and with a high signal intensity on T2WI.

Using CT, the CMN appears as a solid mass arising from kidney. Excretion of contrast material within the mass reflects the possibility that the collecting system is entrapped within the CMN. We used postnatal CT to evaluate the tumor preoperatively. Similarly, postnatal CT features were described in 5 cases, including one upon recurrence, as CT is the imaging modality of choice for the evaluation of recurrence or metastases after initial surgery. According to Matsumura et al., postnatal CT showed that the great vessels were compressed and displaced by the huge CMN mass (14). Montaruli et al. mentioned that CT revealed the arterial vascularization of the ipsilateral kidney (17). Of note, CT images were reported to be relevant to pathological findings (3). Through CT scan, classic $\mathrm{CMN}$ characteristically appears as a large mass with minimal, predominantly peripheral enhancement $(5,17)$. Whereas cellular CMN presents with features of intra-tumoral focal enhancement, as well as cystic lesions, necrosis or hemorrhage, and a heterogeneous mass is mostly the finding, as in our case, and that described by Matsumura et al. (14).

The fetus in our report was delivered at term by elective $\mathrm{CS}$, as in $(2 / 10)$ cases we reviewed, whereas in 7 cases the fetuses were delivered prematurely either through an emergency CS in (at least 5 cases), or through vaginal delivery in (2 cases). It was reported previously that about
$25 \%$ of pregnancies with $\mathrm{CMN}$ result in premature labor and low birth weight infants (6). Notably, polyhydramnios along with its precipitating etiology is among the contributing factors for premature labor. Emergency CS was performed to save the mother of a fetus with CMN that was associated with Ballantyne's syndrome (19).

Male gender was reported in 6 cases including ours, as mentioned in other studies $(1,2,10,13)$. The median birth weight available for $(7 / 10)$ neonates was $2,730(1,030-3,305)$ grams.

Surgery was done for $(9 / 10)$ reviewed cases at a median of 7 [2-49] day-old, likewise, our patient had the surgery at 12-day-old. Emergency surgery was needed due to tumor rupture in one neonate at the age of 2 days (14).

Regarding the pathology in the 10 reviewed cases, classic CMN was more frequent (6/10), followed by cellular (3/10), and one mixed subtype. Isaacs reported a prevalent classic CMN in about two-third of the total cases, followed by cellular, and then mixed variant (13). Comparable results were documented by others $(2,10)$. Although our CMN case was of the aggressive cellular subtype, the presence of ETV6 rearrangement made the prognosis good $(1,2)$.

The risk period for relapse after radical nephrectomy in CMN cases was reported to be short and usually occurred within 12 months after diagnosis (1). In our report, as in (6/10) cases, the patient was cured, however, in one case of cellular CMN, the patient experienced early recurrence, received chemotherapy, and eventually was cured (18). 
Table 2 Congenital mesoblastic nephroma with prenatal MRI diagnosis in the literature review (published from 2010-2018) and the current case

\begin{tabular}{|c|c|c|c|c|c|c|}
\hline Author & Linam et al. & Montaruli et al. & Ko, Kim et al. & Takahashi et al. & Manganaro et al. & Current report \\
\hline \multicolumn{7}{|l|}{ MRI } \\
\hline Polyhydramnios & Yes & No & Yes & Yes & Yes & No \\
\hline $\begin{array}{l}\text { Affected kidney/ } \\
\text { status }\end{array}$ & $\mathrm{R} /$ displaced & $\mathrm{R}$ & L/displaced & R/displaced & $\mathrm{R} /$ enlarged & L/compressed \\
\hline $\begin{array}{l}\text { Mass } \\
\text { description }\end{array}$ & $\begin{array}{l}\text { MRI SS-FSE } \\
\text { sequence: solid } \\
\text { mass arising } \\
\text { from kidney, with } \\
\text { compression of } \\
\text { adjacent liver }\end{array}$ & MRI: CMN & $\begin{array}{l}\text { MRI sequence: HASTE and } \\
\text { axial DWI using } 4 \text { b-values, } \\
\text { showed huge mass at L fetal } \\
\text { retroperitoneum, displaced } \\
\text { aorta, and bowel loops to } R \\
\text { side. R kidney displaced to } R \\
\text { renal fossa, and L kidney not } \\
\text { visualized. Solid portions of } \\
\text { the mass had multiple cystic } \\
\text { spaces, a low signal intensity } \\
\text { on T1WI, and intermediate } \\
\text { signal intensity on T2WI. By } \\
\text { DWI, diffusion restriction } \\
\text { observed in the solid } \\
\text { portions with ADC value of } \\
1.02 \times 10^{-3} \mathrm{~mm}^{2} / \mathrm{sec} \text {. No } \\
\text { hemorrhage or necrosis }\end{array}$ & $\begin{array}{l}\text { Solid tumor } \\
\text { occupying the } \\
\text { kidney }\end{array}$ & $\begin{array}{l}\text { Biparametric } \\
\text { MRI: T2WI and } \\
\text { DWI showed } \\
\text { enlarged R } \\
\text { kidney with } \\
\text { inhomogeneous } \\
\text { and isointense } \\
\text { mass containing } \\
\text { cystic lesions on } \\
\text { T2WI and areas } \\
\text { of restriction of } \\
\text { the diffusion on } \\
\text { DWI }\end{array}$ & $\begin{array}{l}\text { Large well- } \\
\text { circumscribed } \\
\text { solid } \\
\text { heterogeneous } \\
\text { mass, } \\
\text { containing } \\
\text { some cystic } \\
\text { areas with } \\
\text { low intensity } \\
\text { on T1WI, } \\
\text { intermediate } \\
\text { intensity on } \\
\text { T2WI, and } \\
\text { signal restriction } \\
\text { in DWI }\end{array}$ \\
\hline Size $(\mathrm{cm})$ & NA & NA & $8 \times 9 \times 10$ & NA & NA & $6.3 \times 5.7 \times 5.3$ \\
\hline Delivery mode & eCs & NA & eCS & eCS & VD & CS \\
\hline $\begin{array}{l}\text { Gestational age } \\
(w k s) / s e x\end{array}$ & 29/NA & $40 / \mathrm{M}$ & $30 / F$ & $28 / F$ & $34 / F$ & $38 / \mathrm{M}$ \\
\hline $\begin{array}{l}\text { Birth weight } \\
\text { (grams) }\end{array}$ & 1,200 & NA & NA & 1,210 & NA & 3,560 \\
\hline $\begin{array}{l}\text { Apgar scores at } \\
\text { ( } 1 \text { and } 5 \text { minutes) }\end{array}$ & 6 and 9 & NA & NA & 3 and 6 & NA & 9 and 10 \\
\hline
\end{tabular}

Table 2 (continued) 
Table 2 (continued)

\begin{tabular}{|c|c|c|c|c|c|c|}
\hline Author & Linam et al. & Montaruli et al. & Ko, Kim et al. & Takahashi et al. & Manganaro et al. & Current report \\
\hline $\begin{array}{l}\text { Age at surgery } \\
\text { (days) }\end{array}$ & 49 & 10 & 5 & 6 & NA & 12 \\
\hline $\begin{array}{l}\text { Histopathology } \\
\text { CMN subtype }\end{array}$ & Mixed & Classic & Cellular & Classic & Classic & Cellular \\
\hline $\begin{array}{l}\text { Genetic } \\
\text { evaluation }\end{array}$ & ND & ND & ND & ND & ND & $\begin{array}{l}\text { ETV6 gene } \\
\text { rearrangement }\end{array}$ \\
\hline $\begin{array}{l}\text { Outcome/follow } \\
\text { up age }\end{array}$ & NA & Cured/NA & $\begin{array}{l}\text { Relapsed at } 7 \text {-week-old, } \\
\text { treated by chemotherapy, } \\
\text { then cured/ } 9 \text { months }\end{array}$ & $\begin{array}{l}\text { Renal } \\
\text { dysfunction/ } \\
1 \text { year }\end{array}$ & Cured/6 months & Cured/3 years \\
\hline
\end{tabular}

${ }^{*}$, this patient required postoperative imaging due to recurrence. ADC, apparent diffusion coefficient; CDS, color Doppler sonography; CMN, congenital mesoblastic nephroma; CS, Cesarean-section; CT, computed tomography; DWI, diffusion weighted images; eCS, emergency Cesarean-section; F, female; GA, gestational age; HASTE, Half-Fourier acquisition single-shot turbo-spin-echo; L, left; NA, not available; M, male; MRI, magnetic resonance imaging; ND, not done; R, right; SS-FSE, single shot fast spin echo; T1WI, T1 weighted images; T2WI, T2 weighted images; US, ultrasound; VD, vaginal delivery; wks, weeks.

\section{Acknowledgments}

Funding: This work was supported by Shanghai Municipal Commission of Health and Family Planning (grant number: 201840165).

\section{Footnote}

Reporting Checklist: The authors have completed the CARE reporting checklist. Available at https://tp.amegroups.com/ article/view/10.21037/tp-21-289/rc 
Peer Review File: Available at https://tp.amegroups.com/ article/view/10.21037/tp-21-289/prf

Conflicts of Interest: All authors have completed the ICMJE uniform disclosure form (available at https://tp.amegroups. com/article/view/10.21037/tp-21-289/coif). The authors have no conflicts of interest to declare.

Ethical Statement: The authors are accountable for all aspects of the work in ensuring that questions related to the accuracy or integrity of any part of the work are appropriately investigated and resolved. All procedures performed in studies involving human participants were in accordance with the ethical standards of the institutional and/or national research committee(s) and with the Helsinki Declaration (as revised in 2013). Written informed consent was obtained from the child's parent. A copy of the written consent is available for review by the editorial office of this journal.

Open Access Statement: This is an Open Access article distributed in accordance with the Creative Commons Attribution-NonCommercial-NoDerivs 4.0 International License (CC BY-NC-ND 4.0), which permits the noncommercial replication and distribution of the article with the strict proviso that no changes or edits are made and the original work is properly cited (including links to both the formal publication through the relevant DOI and the license). See: https://creativecommons.org/licenses/by-nc-nd/4.0/.

\section{References}

1. Gooskens SL, Houwing ME, Vujanic GM, et al. Congenital mesoblastic nephroma 50 years after its recognition: A narrative review. Pediatr Blood Cancer 2017.

2. England RJ, Haider N, Vujanic GM, et al. Mesoblastic nephroma: a report of the United Kingdom Children's Cancer and Leukaemia Group (CCLG). Pediatr Blood Cancer 2011;56:744-8.

3. Chaudry G, Perez-Atayde AR, Ngan BY, et al. Imaging of congenital mesoblastic nephroma with pathological correlation. Pediatr Radiol 2009;39:1080-6.

4. Won HS, Jung E, Lee PR, et al. Prenatal detection of mesoblastic nephroma by sonography and magnetic resonance imaging. Ultrasound Obstet Gynecol 2002;19:197-9.

5. Irsutti $M$, Puget $C$, Baunin $C$, et al. Mesoblastic nephroma: prenatal ultrasonographic and MRI features. Pediatr
Radiol 2000;30:147-50.

6. Linam LE, Yu X, Calvo-Garcia MA, et al. Contribution of magnetic resonance imaging to prenatal differential diagnosis of renal tumors: report of two cases and review of the literature. Fetal Diagn Ther 2010;28:100-8.

7. Saleem SN. Fetal MRI: An approach to practice: A review. J Adv Res 2014;5:507-23.

8. van den Heuvel-Eibrink MM, Grundy P, Graf N, et al. Characteristics and survival of 750 children diagnosed with a renal tumor in the first seven months of life: A collaborative study by the SIOP/GPOH/SFOP, NWTSG, and UKCCSG Wilms tumor study groups. Pediatr Blood Cancer 2008;50:1130-4.

9. Sheth MM, Cai G, Goodman TR. AIRP best cases in radiologic-pathologic correlation: congenital mesoblastic nephroma. Radiographics 2012;32:99-103.

10. Furtwaengler R, Reinhard H, Leuschner I, et al. Mesoblastic nephroma--a report from the Gesellschaft fur Pädiatrische Onkologie und Hämatologie (GPOH). Cancer 2006;106:2275-83.

11. Riccabona M. Imaging of renal tumours in infancy and childhood. Eur Radiol 2003;13 Suppl 4:L116-29.

12. Vokuhl C, Nourkami-Tutdibi N, Furtwängler R, et al. ETV6-NTRK3 in congenital mesoblastic nephroma: A report of the SIOP/GPOH nephroblastoma study. Pediatr Blood Cancer 2018.

13. Isaacs H Jr. Fetal and neonatal renal tumors. J Pediatr Surg 2008;43:1587-95.

14. Matsumura M, Nishi T, Sasaki $Y$, et al. Prenatal diagnosis and treatment strategy for congenital mesoblastic nephroma. J Pediatr Surg 1993;28:1607-9.

15. Chen WY, Lin CN, Chao CS, et al. Prenatal diagnosis of congenital mesoblastic nephroma in mid-second trimester by sonography and magnetic resonance imaging. Prenat Diagn 2003;23:927-31.

16. Yamamoto N, Yoshizako T, Uchida N, et al. Mesoblastic nephroma: a case report of prenatal detection by MR imaging. Magn Reson Med Sci 2006;5:47-50.

17. Montaruli E, Fouquet V. Prenatal diagnosis of congenital mesoblastic nephroma. Fetal Diagn Ther 2013;33:79-80.

18. Ko SM, Kim MJ, Im YJ, et al. Cellular mesoblastic nephroma with liver metastasis in a neonate: prenatal and postnatal diffusion-weighted MR imaging. Korean J Radiol 2013;14:361-5.

19. Takahashi H, Matsubara S, Kuwata T, et al. Maternal manifestation of Ballantyne's syndrome occurring concomitantly with the development of fetal congenital 
mesoblastic nephroma. J Obstet Gynaecol Res 2014;40:1114-7.

20. Manganaro L, Bernardo S, Antonelli A, et al. Fetal biparametric MR imaging in the diagnosis of congenital mesoblastic nephroma. Turk J Urol 2018;44:278-80.

Erratum in: Turk J Urol 2019;45:76.

Cite this article as: Liu T, Al-Kzayer LFY, Sarsam SN, Chen L, Saeed RM, Ali KH, Nakazawa Y. Cellular congenital mesoblastic nephroma detected by prenatal MRI: a case report and literature review. Transl Pediatr 2022;11(1):163-173. doi: $10.21037 /$ tp-21-289 